UNIVERSIDADE ESTADUAL DE FEIRA DE SANTANA

Autorizada pelo Decreto Federal $n^{\circ} 77.496$ de $27 / 04 / 76$
Recredenciamento pelo Decreto $n^{\circ} 17.228$ de $25 / 11 / 2016$

PPPG

PRÓ-REITORIA DE PESQUISA E PÓS-GRADUAÇÃO

COORDENAÇÃO DE INICIAÇÃO CIENTÍFICA

XXIII SEMINÁRIO DE INICIACCÃO CIENTÍFICA DA UEFS

SEMANA NACIONAL DE CIENTÍFICA E TECNOLÓGICA - 2019

\title{
AVALIAÇÃO DA ATIVIDADE ANTINOCICEPTIVA DE POLISSACARÍDEO ISOLADO DO FUNGO Torula herbarum
}

\author{
Daniela da Silva Borges ${ }^{1}$; Flávia Oliveira de Lima²; Sandra Aparecida de Assis $^{3}$ \\ 1. Bolsista FAPESB, Graduanda em Farmácia, Universidade Estadual de Feira de Santana, e-mail: \\ danielaborges856@gmail.com \\ 2. Orientadora, Departamento de Saúde, Universidade Estadual de Feira de Santana, email: \\ flavia_lima2000@yahoo.com.br \\ 3. Colaborador, Departamento de Saúde, Universidade Estadual de Feira de Santana, email: \\ sandrinhaassis@yahoo.com.br
}

PALAVRAS-CHAVE: Atividade antinociceptiva, Polissacarídeo, Produtos naturais

\section{INTRODUÇÃO}

A dor é um sintoma existente em muitas condições clínicas e pode causar absenteísmo, incapacidade temporária ou permanente, morbidade e elevados custos ao sistema de saúde, sendo considerada um problema econômico, social e de saúde pública (PICAVET; SCHOUTEN, 2003).

Existe uma gama de analgésicos clinicamente disponíveis para o controle da dor, entretanto, em muitos casos, esses fármacos apresentam limitações, tais como expressivos efeitos adversos, pacientes refratários à terapia farmacológica, bem como a não responsividade ao tratamento em alguns casos (CHOPADE; MULLA, 2010).

Diante do proposto, justifica-se este trabalho, tendo em vista a necessidade de desenvolvimento de novas opções terapêuticas para o controle da dor, em virtude da alta incidência de efeitos indesejáveis dos analgésicos disponíveis e sua baixa eficácia em alguns tipos de dor. Assim, o presente trabalho teve como objetivo avaliar, através de ensaios farmacológicos, a possível atividade antinociceptiva de polissacarídeo isolado do fungo Torula herbarum (POLI7008), em modelos experimentais de dor em camundongos.

\section{MATERIAIS E MÉTODOS}

O polissacarídeo isolado do fungo Torula herbarum, obtido a partir da Coleção de Cultura de Microrganismos da Bahia (CCMB, Feira de Santana, Brasil), e caracterizado estruturalmente por técnicas de espectroscopia em infravermelho (FTIR) e ressonância magnética nuclear $\left(\mathrm{RMN}-{ }^{13} \mathrm{C}\right)$. Os experimentos foram realizados com camundongos machos da linhagem Swiss Webster (25-30g). O efeito antinociceptivo do 
POLI7008 foi avaliado pelos testes de contorções abdominais (COLLIER, et al. 1968) e teste de formalina (DUBUISSON; DENNIS, 1977). O efeito sobre o desempenho motor foi determinado pelos testes de rota rod (ROSLAND; HUNSKAAR; HOLE, 1990) e campo aberto (MACHADO et al., 2007). Os resultados obtidos foram analisados estatisticamente e representados como média \pm E.P.M de 6 animais por grupo, sendo os grupos experimentais comparados pelo teste one-way ANOVA, seguido do teste Bonferroni. $O$ nível de significância foi de $p<0,05$. Este trabalho foi aprovado pela Comissão de Ética em Experimentação Animal da UEFS (006/2013).

\section{RESULTADOS E/OU DISCUSSÃO}

A atividade antinociceptiva do POLI7008 foi inicialmente avaliada no teste de contorções abdominais induzidas pelo ácido acético. $\mathrm{O}$ modelo de contorções abdominais em camundongo é uma ferramenta de triagem para a avaliação das propriedades analgésicas ou antiinflamatória de novos agentes (COLLIER et al., 1968). Os animais tratados pela administração i.p. do POLI7008 nas doses de 9 e $27 \mathrm{mg} / \mathrm{kg}$ produziram uma redução significante e dose dependente do número de contorções abdominais induzidas pelo ácido acético $(\mathrm{p}<0,05)$. A morfina $(5 \mathrm{mg} / \mathrm{kg}$, s.c. $)$ utilizada como controle positivo, também inibiu significantemente o número de contorções abdominais induzida pelo ácido acético $(\mathrm{p}<0,05)$.

Para confirmar o efeito antinociceptivo do POLI7008 foi realizado o teste de nocicepção induzida pela formalina. As respostas comportamentais à formalina seguem um padrão bifásico composto 02 fases: uma fase inicial aguda (fase neurogênica) e outra fase tardia (fase inflamatória) (DUBUISSON; DENNIS, 1977). Na fase neurogênica ou fase inicial (0-05 min) foi possível observar que o pré-tratamento com o POLI7008 (3, 9 e 27mg/Kg) não inibiu o comportamento nociceptivo dos animais. Na fase tardia (15-30min) o pré-tratamento com o POLI7008 (9 e $27 \mathrm{mg} / \mathrm{Kg}$ ) foi capaz de inibir significantemente o comportamento nociceptivo induzido pela injeção de formalina $(\mathrm{p}<0,05)$. A morfina $(5 \mathrm{mg} / \mathrm{kg}$, s.c.) fármaco de referência, apresentou ação antinociceptiva em ambas as fases. Considerando que o tratamento com POLI7008 foi capaz de reduzir a nocicepção inflamatória do teste de formalina, pode-se inferir que o efeito antinociceptivo do POLI7008 resulta, provavelmente, de uma ação antiinflamatória, que por sua vez, reduz a sensibilização dos terminais nociceptivos periféricos, bem como as transmissões de potenciais de ação à raiz dorsal da medula espinhal, consequentemente, reduzindo a hiperalgesia resultante (FERREIRA, 1972).

Drogas com ação depressora sobre o sistema nervoso central e muscular podem reduzir a coordenação motora em animais, bem como a expressão de comportamentos nociceptivos (SOJA et al., 2002). Posto que os testes de avaliação de atividade antinociceptiva exigem respostas motoras dos animais, resultados falsos positivos poderiam ser obtidos, caso ocorresse perda da coordenação motora dos animais por sedação e/ou relaxamento muscular. Neste sentido, foram realizados o teste de campo 
aberto e rota Rod com o intuito de verificar a possível interferência do POLI7008 na função locomotora dos animais.

A administração intraperitoneal do POLI7008 $(27 \mathrm{mg} / \mathrm{kg})$ não alterou a atividade locomotora dos camundongos quando comparado ao grupo controle negativo $(p>0,05)$. O tratamento com diazepam $(10 \mathrm{mg} / \mathrm{kg}$, i.p.), controle positivo, apresentou redução significativa do número de quadrados percorridos no campo aberto $(\mathrm{p}<0,05)$. Do mesmo modo, observou-se que o grupo tratado com o POLI7008 não modificou o tempo de permanência dos animais no cilindro giratório, quando comparado ao grupo controle negativo ( $p>0,05)$. O diazepam $(10 \mathrm{mg} / \mathrm{kg})$, utilizado como controle positivo, apresentou redução significativa no tempo de permanência dos animais no cilindro giratório $(\mathrm{p}<0,05)$. Esses resultados validam a especificidade da antinocicepção sugerida pelos testes nociceptivos.

\section{CONSIDERAÇÕES FINAIS}

Os resultados obtidos demonstraram que o polissacarídeo isolado do fungo $T$. herbarum (POLI7008), nas doses de 9 e $27 \mathrm{mg} / \mathrm{kg}$, possui atividade antinociceptiva em modelos experimentais de dor. Além disso, nas doses terapêuticas testadas não induziu alteração da função motora. Sendo assim, os resultados obtidos fornecem a primeira evidência de que o POLI7008 é um agente antinociceptivo, tornando-o promissor para estudos e desenvolvimento de fármacos analgésicos.

\section{REFERÊNCIAS}

COLLIER, H. O. J.; DINNEEN, L. C.; JOHNSON, C. A.; SCHNEIDER, C. 1968. The abdominal constriction response and its suppression by analgesic drugs in the mouse. Br. J. Pharmacol. Chemother 32 (2): 295-310.

CHOPADE, A. R.; MULlA, W. A. 2010. Novel strategies for the treatment of inflammatory hyperalgesia. Eur J Clin Pharmacol 66 (5): 429-44.

DUBUISSON, D.; S. G. DENNIS. 1977. The formalin test: a quantitative study of the analgesic effects of morphine, meperidine, and brain stem stimulation in rats and cats. Pain4 2: 161-74.

FERREIRA, S.H. 1972. Prostaglandins, aspirin-like drugs and analgesia. Nat. Biol 20: 200-203.

MACHADO, D. G.; KASTER, M. P.; BINFARÉ, R. W.; DIAS, M.; SANTOS, A. R. S.; PIZZOLATTI, M. G.; BRIGHENTE, I. M. C.; RODRIGUES, A. L. S. 2007. Antidepressant-like effect of the extract from leaves of Schinusmolles L. in mice: evidence for the involvement of the monoaminergic system. Prog. Neuro-psychopharmacol. Biological Psychiatry 31: 412-428. 
PICAVET, H. S.; SCHOUTEN, J. S. 2003. Musculoskeletal pain in the Netherlands, prevalences, consequences and risk groups, the DMC(3)-study. Pain 102 (1-2): 167-78.

ROSLAND, J.H.; HUNSKAAR, S.; HOLE, K. 1990. Diazepam attenuates morphine antinociception test-dependently in mice. Pharmacol. Toxicol 66 (5): 382-386.

SOJA. P. C. et al. 2000. Activation of ATP-sensitive K+ channels: mechanism of perepheralanti nociceptive action of the nitric oxide donor, sodium nitroprusside. Eur. $J$ Pharmacol 400: 67-71. 